\title{
A África, o Sul e as ciências sociais brasileiras: descolonização e abertura
}

\section{Marcelo C. Rosa*}

Resumo: O texto introduz questões recentes sobre a relação entre as ciências sociais na África e no Brasil, inserindo-as no debate sobre as sociologias do Sul e a geopolítica do conhecimento na produção de teoria social. A partir da noção de sociologia não exemplar são apresentados alguns dos possíveis caminhos teórico-metodológicos que possibilitariam um posicionamento mais simétrico para a produção de conhecimento localizada fora da Euro-América.

Palavras-chave: descolonização, África, sociologias do Sul, sociologia não exemplar, teoria social.

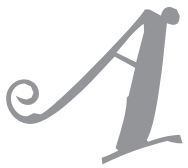

década de 2000 assistiu a um movimento muito interessante nas ciências sociais brasileiras. Pela primeira vez, pesquisadores tiveram incentivos institucionais reais para realizarem pesquisas fora do país ${ }^{1}$. Num momento em que estavam no auge iniciativas como o Fórum Social Mundial e coalizões governamentais como Ibas e Brics², agências de fomento criaram mecanismos específicos para aproximar pesquisadoras nacionais de colegas africanos. Lentamente começamos, neste lado do Atlântico, a tomar contato com teorias e processos sociais produzidos naquele continente.

Ainda que o caminho das relações acadêmicas continue privilegiando encontros entre brasileiras e africanas ${ }^{3}$ nas universidades classicamente coloniais da Europa e dos Estados Unidos, com a nova conjuntura certas coisas começam a mudar. Em nossas viagens de pesquisa já trazemos não apenas souvenirs ou dados de um continente remoto que confirmam as arbitrárias descrições presentes em clássicos da antropologia e da sociologia. Passamos a contrabandear livros, artigos e amizades que trazem desafios imensos para todos e todas. O maior deles talvez seja reconhecer a importância dos conhecimentos produzidos naquela região para pensar a própria maneira como narramos a história das ciências sociais e para desafiar nossos modelos teóricos. Neste ponto, não há dúvida que podemos pensar nossas relações com a África na mesma chave em que se tem pensado as relações Sul-Sul.

Diante de tal contexto, se faz necessário pensar em como dar vida acadêmica às contribuições de nossos colegas do Sul para a produção do conhecimento em ciências sociais. Na maior parte dos países da África e no Brasil, cursos de teoria social são completamente dominados pela ideia de que teoria é algo que se produz na Euro-América (e.g. no Brasil separamos radicalmente cursos de teoria social dos

\author{
* Professor associado \\ do Departamento \\ de Sociologia/UnB \\ e pesquisador do \\ CNPq. É coordenador \\ do Laboratório \\ de Sociologia Não \\ Exemplar $<w w w$. \\ naoexemplar.com>. \\ <marcelorosa@ \\ gmail.com>.
}

1. Os organizadores deste dossiê foram, por exemplo, contemplados em momentos distintos pelo Edital Pro-África do CNPq.

2. Fórum de Diálogo Índia, Brasil e África do Sul (Ibas); Brasil, Rússia, Índia, China e África do Sul (Brics).

3. O uso da flexão feminina de gênero em algumas partes do texto visa, sobretudo, chamar atenção para o fato de que, na sociologia, a teoria é em geral identificada apenas com autores do sexo masculino. 
4. A expressão EuroAmérica é adotada por autores como Law (2004), Comaroff e Comaroff (2011) e Anzaldúa (Anzaldúa e Reuman, 2000).

5. Para análises contemporâneas no Brasil da obra de S. Alatas, ver os trabalho de Maia (2014) e Maia e Caruso (2012). cursos de pensamento social brasileiro) (Connell, 2007). Na mesma chave, consideramos normal que, entre os textos teóricos considerados clássicos da sociologia, não haja contribuições de mulheres, nem euro-americanas ${ }^{4}$ e nem de outros continentes.

Outra consequência importante é que tendemos a reconhecer a África e a sermos reconhecidos pelos colegas daquela região por meio de pesquisa e descrições publicadas a partir das agendas euro-americanas. Nessa condição, tendemos a olhar seletivamente tanto de um lado como de outro, na busca de temas como pobreza, desigualdades, dominação e patriarcalismo entre outros termos derrogatórios. Um bom exemplo é a crítica dentro da teoria feminista feita por Mohanty (2008) à imposição da categoria eivada de preconceitos "mulheres do Terceiro Mundo" por parte de autoras ocidentais para descrever relações de gênero em países do Sul. Neste caso, a propriedade sociológica que permitiria um olhar geral sobre as experiências destas mulheres seria a ausência de certas características positivas atribuídas às mulheres de vanguarda (de um suposto Primeiro Mundo). Em última instância, nós, do Sul, seríamos próximas porque somos defeituosas em relações a certos padrões normativos ou, ainda pior, porque somos vítimas.

Seguindo outro clássico argumento proposto por Hountoundji (2009), essas práticas marcam uma diferença fundamental entre as noções de "conhecimentos de África" (um conhecimento no qual o africano é apenas objeto, como na clássica antropologia africanista) e de conhecimentos africanos (formas de compreender o mundo social produzidas por africanos) e que poderíamos estender para conhecimentos sobre mulheres versus conhecimento de mulheres, conhecimentos sobre negras versus conhecimentos de negras, entre outras.

Este processo foi descrito por S. Alatas (2000) como imperialismo intelectual, fenômeno que combinado com os já conhecidos projetos de dominação política e econômica trabalhados pela literatura pós-colonial (Chakrabarty, 1997; Smith, 1999) contribui para a produção de uma mentalidade cativa ${ }^{5}$. Esta atitude acadêmica naturaliza, por meio de uma série de processos técnicos e políticos, as intelectuais do Sul como ocupando posições subalternas na divisão do trabalho intelectual. A mais importante destas divisões é entre quem produz teorias e métodos e aquelas que produzem os dados (Connell, 1997). Hountoundji (1997) a descreve como uma lógica da "extroversão", que, para Neves e Costa Lima (2012) culmina em processo no qual os cientistas das chamadas periferias se tornam hábeis em "administrar a irrelevância" de suas próprias produções. No Sul, o prestígio intelectual converte-se, em muitos casos, na capacidade de demonstrar usos eficazes das teorias/modelos produzidos em outros contextos para classificarmos a nós mesmos. 
Este debate nos conduz, inevitavelmente, ao questionamento do modo pelo qual compreendemos a questão do universalismo em nossas disciplinas. Seria justo pensar que teorias feitas com base na experiência de uma pequena porção da humanidade são capazes de se estender para todos os lugares? Seriam todos os fenômenos empíricos descritos em nossas pesquisas passíveis de serem "torcidos" e traduzidos para as grandes narrativas da teoria social? Qual seria o custo intelectual desta translação? O que estaria embutido numa busca acrítica do universalismo?

Nas sociologias, este dilema foi, por exemplo, refletido nos debates sobre as formas de lidar com a noção de Modernidade. Em oposição aos modelos meramente evolutivos e que localizavam a experiência da Modernidade como sendo apenas europeia, emergiram, nas últimas décadas, perspectivas como a das "modernidades múltiplas" (Eisenstad, 2000; Schmidt, 2011), da "terceira fase da modernidade (Domingues, 2009) ou das "nossas modernidades" (Chaterjee, 1997) ${ }^{6}$. Em cada uma dessas propostas, com métodos e perspectivas distintas, se procurou dar algum valor aos conteúdos positivos impressos pela África, América-Latina e Ásia, nas narrativas mestras da sociologia e, ao mesmo tempo, repensar os limites de sua aplicação.

A partir de uma visão mais cética, mas ainda preocupada com os efeitos da modernidade fora da Euro-América, autores como Hall (1992), Spivak (1988), Mignolo (2011), Quijano (2000), Santos e Meneses (2009) denunciaram os efeitos deletérios (racismo, violência epistêmica e muitos outros) dos olhares que consideram apenas as agências "modernas" na constituição dos saberes nas ciências sociais.

Propositalmente desviando das narrativas da modernidade, intelectuais como Mama (2008), Anzaldúa (1987), S. F. Alatas (2000; 2010), R. Connell (2007), Law (2004), Houtounji (1997), Walsh (2007) e Archie Mafeje (neste volume, apresentado pelo texto de Borges et alii) ousaram responder criticamente a este tema propondo uma volta ao clássico debate entre o nomotético e ideográfico nas ciências sociais. De forma resumida, muitos deles tendo produzido seus textos antes do reconhecido Provincializing Europe de D. Chakrabarty, todos estes autores e autoras vislumbram a descolonização e a abertura das ciências sociais como um processo de repensar o universalismo, a partir de experiências locais e específicas. Ou seja, trata-se de um movimento que busca reintroduzir o ideográfico (algumas vezes nomeado endógeno e/ou indígena) com pretensões de se repensar e tencionar os limites mais amplos da disciplina e não apenas como forma de valorizar uma suposta propriedade local. Todos e todas, buscam reconhecer a universalização de métodos e teorias nas ciências sociais como um processo problemático que não pode ser entendido fora de uma geopolítica do conhecimento. De meu ponto de vista, a questão que emerge
6. Tavolaro (2005)

adentra este debate a partir da crítica à noção de "modernidade brasileira". 
7. Diversos debates promovidos por presidentes da Associação Internacional de Sociologia tentaram lidar com o dilema da universalização e das relações de poder no interior da disciplina. São exemplos o texto publicado por Archer (1991), Sztompka (2011) e Burawoy (2011). desta agenda é justamente como produzir teorias sobre o "mundo", sem que elas sejam sobre um "mundo"?.

Apesar da visão colonial e colonizadora que as próprias ciências sociais ajudam a difundir, os trânsitos sul-atlânticos já permitem aos olhares mais atentos reconhecer desafios teóricos metodológicos propostos nestas bandas do mundo (Nyamnhjoh, 2012; Adesina, 2002, Maia, 2014). Aqui, talvez, a metáfora da dupla consciência, forjada por W. E. B. Dubois, para falar da condição do negro nos Estados Unidos do final do Século XIX, seja a mais apropriada para lidar com os desafios de se fazer sociologia no Sul do mundo. Nossas posições intelectuais devem, o tempo todo, estar atentas ao que se conheceu como a produção global da sociologia euro-americana e, ao mesmo tempo, estar cientes de que temos por tarefa desenvolver teorias e métodos a partir de nossos próprios contextos (como sugere a releitura que o texto de Borges et alii fazem da obra do antropólogo sul-africano Archie Mafeje).

Nesse sentido, apontei em Rosa $(2014 ; 2013)$ que os caminhos para uma "sociologia do Sul" não necessariamente levam à busca de uma suposta unidade de quem produz conhecimento em situações geopolíticas não hegemônicas. Este movimento tende a ganhar força analítica apenas quando argumentos/atores/processos/histórias estrategicamente apresentados como regionais são mobilizados para sustentar a crítica aos padrões, métodos ou narrativas dominantes na disciplina. Suas possíveis virtudes, ainda pouco exploradas, encontram-se justamente na irredutível pluralidade de métodos e contextos empíricos que nos são apresentados. Entre as diversas alternativas existente, sugeri, inspirado em certos estudos sobre gênero (Connell, 2011; Anzaldúa, 1987) e sobre a questão da terra (Verran, 1998), uma teoria do Sul focada na "ontoformatividade". Uma sociologia que se dedique, aproveitando contextos empíricos e arranjos intelectuais específicos e ainda pouco explorados, à produção de métodos e de novos objetos que ampliem e desafiem os atuais parâmetros que dominam a disciplina e a mantêm refém de poucos objetos teóricos exemplares.

Ampliar tanto métodos como objetos nesta chave abriria algumas portas para o que chamo de uma sociologia não exemplar, que se caracterizaria primordialmente por uma postura metodológica de evitar a definição de nossa investigação a partir de narrativas prontas (exemplares). Dois princípios teórico-metodológicos seriam centrais nesta proposta. O primeiro deles é evitar, a priori, a definição de um objeto por comparação e derivação (dilema apresentado neste dossiê pelos trabalhos de Mutzenberg sobre movimentos sociais e de Mabin sobre o urbanismo). Como no contexto descrito da geopolítica do conhecimento em ciências sociais, certos processos e agências têm sido historicamente privilegiados, temos a tendência de transferir suas propriedades para definir coisas que ainda não conhecemos. É assim 
que as noções de cidades, os movimentos sociais, a terra, as mulheres e a própria noção do que é digno de ser chamado de "social" circulam, estabilizam-se e colonizam espaços acadêmicos (Latour, 2005). Em muitos casos, elas são usadas contra as pessoas que pesquisamos para acusar sua incompletude. Sua consequência imediata é a consagração de marcadores sociais normativos sejam eles evolucionistas (transição, desenvolvimento, civilização, racionalização, secularização) ou dualistas (rural/urbano, moderno/atrasado, mulheres/homens, público/privado) que se tornam parâmetros de análise. Numa sociologia não exemplar, a análise recairia não nos tipos mais puros ou homogêneos (que em geral são estatisticamente minoritários), mas nas situações mais confusas e difíceis de serem descritas com a linguagem disponível. Não por acaso, trata-se de uma tendência nas descrições da vida social do Sul o uso de termos como confusão, bagunça, desordem, entre outros (de meu ponto de vista, indicam mais do que uma forma social um limite dos conceitos e propostas teóricas disponíveis).

O segundo desafio é explorar novas fontes. É aqui que entram as análises da literatura (como propõe o texto de E. Veras a partir do estudo da formação da literatura no Moçambique) $)^{8}$, das oralidades, do espaço, de universos oníricos, de biografias e de experiências de sujeitos que cruzam espaços teoricamente liminares (como das mulheres pentecostais descritas no texto de L. Kamp).

Um último e fundamental passo seria, após reconhecermos que se produzem questões teóricos-metodológicas relevantes no Sul, construir canais para que este conhecimento circule para além das fronteiras nacionais e regionais. Ainda em conexão com a geopolítica do conhecimento, os clássicos euro-americanos se tornaram clássicos também porque suas teorias e formas de conhecer foram amplamente distribuídas em escala global. Superar a colonialidade do saber (Lander, 2000) exige não apenas conferir espaço para que formas de conhecimento não mapeadas ganhem as páginas de nossos textos, requer ainda que os conhecimentos já produzidos circulem em livros, revistas, congressos e nos programas de nossos cursos nas universidades. O trabalho militante de algumas autoras institucionais, como a Associação Internacional de Sociologia, logra, em seus congressos e publicações (Patel, 2010; Burawoy, 2010; Arjomand \& Reis, 2013), ampliar a diversidade de perspectivas e tradições representadas nos principais fóruns da disciplina.

De meu ponto de vista, este movimento apenas se inicia e, para que tenha algum futuro, precisa ser replicado com mais frequências em encontros e publicações sediados nos países do Sul, especialmente na América Latina e na África. Tal projeto envolveria, em primeiro lugar, a publicação em línguas locais de textos produzidos nos demais países do Sul para que a intimidade (seja no Brasil ou na África) com esta literatura se inicie desde a graduação. Concomitantemente, é preciso também
8. É preciso distinguir o uso nas ciências sociais da literatura como objeto ou como fonte. 
que publiquemos reflexões críticas sobre as teorias produzidas nestas regiões, juntamente com pesquisas que ofereçam olhares cruzados que nos ajudem esclarecer o que, afinal de contas, aprendemos nestas relações acadêmicas.

Este foi principal objetivo ao propormos um número de uma tradicional revista brasileira que tem como tema as relações África-Brasil. Nossa opção é trazer questões empíricas e teóricas contemporâneas que contribuam para aumentar a circulação de ideias e desafios no âmbito das ciências sociais. Até onde os tradicionais modos de se compreender a literatura, a religião e os movimentos sociais foram e são suficientes para dar conta das formas pelas quais coletividades vêm sendo pensadas e postas em prática no continente africano e no Brasil? Nas páginas seguintes encontraremos respostas diversas e por vezes divergentes a estas indagações, elaboradas por pesquisadoras e pesquisadores localizados em centros de diversas partes do mundo, mas que toparam a ideia de se abrirem para este desafio contemporâneo.

Abstract: The paper introduces the contemporary debates on the relation of social sciences in Africa and Brazil by framing them both under the current discussion about the "sociologies of the south" and the ones on "the geopolitics of knowledge". Deploying the notion of a "non-exemplary sociology", I seek to present some possible theoretical and methodological ways that would enable a more symmetric positioning of the knowledge produced outside the Euro-America.

Keywords: decolonization, Africa, sociologies of the South, non-exemplary sociology, social theory.

\section{Referências}

ADESINA, Jimmy. Sociology and Yorùbá Studies: epistemic intervention or doing sociology in the "vernacular"? African Sociological Review, v. 6, n. 1, p. 91-114, 2002.

ALATAS, Syed Farid. A definição e os tipos de discursos alternativos. Estudos Históricos, v. 23, n. 46, p. 225-245, 2010.

- Intelectual imperialism. Definitions, threats and problems. Southeast Asian Journal of Social Sciences, v. 28, n. 1, p. 23-45, 2000.

- The myth of the lazy native: A study of the image of the Malays, Filipinos and Javanese from the 16th to the 20th century and its function in the ideology of colonial capitalism. London: Frank Kass, 1997.

ANZALDÚA, G.; REUMAN, A. E. Coming into play: an interview with Gloria Anzaldúa. Melus, v. 25, n. 2, p. 3-45, 2000. 
ANZALDÚA, Gloria. Borderlands/La Frontera: the new mestiza. San Francisco: Spinter/Aunt Lute, 1987.

ARCHER, Margaret. Sociology for one world: Unity and Diversity (Presidential Address). International Sociology, v. 6, n. 2, p. 131-147, 1991.

ARJOMAND, Said; REIS, Elisa P. (Eds.). Worlds of difference. Sage (Studies in International Sociology), 2013.

BURAWOY, M.; CHANG, M.; HSIE, M. F. Facing an unequal world: challenges for a global sociology. Volume One: Introduction, Latin America and Africa. Taiwan: Institute of Sociology, Academia Sinica, Council of National Associations of the International Sociological Association, 2010.

BURAWOY, Michael. The last positivist. Contemporary Sociology, v. 40, n. 4, p. 396404, 2011.

CHAKRABARTY, Dipesh. Provincializing Europe: post-colonial tough and historical difference. Princeton: Princeton University Press, 2000.

. Postocoloniaty and the artifice of history. Who speaks for the Indian pasts? In: GUHA, R. A subaltern studies reader 1986-1995. Minneapolis (MN): University of Minessota Press, 1997.

ChATTERJEe, Partha. Our Modernity. Dakar: Codesria; Sephis, 1997.

COMAROFF, Jean; COMAROFF, John. Theory from the South. Or how Euro-America is evolving toward Africa. London: Paradigm Publishers, 2011.

CONNELL, Raewyn. Gender and social justice: Southern perspectives. South African Review of Sociology, v. 42 n. 3, p. 103-115, 2011.

- Southern Theory: the global dynamics of knowledge in social sciences. Cambridge: Polity, 2007.

DOMINGUES, Jose M. Modernity and modernizing moves: Latin America in comparative perspective. Theory, Culture and Society, v. 26, n. 7-8, p. 208-227, 2009.

EISENSTADT, Shmuel N. Multiple modernities. Daedalus, 129, n. 1, p. 1-29, 2000. 
HALL, Stuart. The question of cultural identity. In: HALL, Stuart; HELD, David; McGREW, Anthony. Modernity and its futures, p. 274-316. Cambridge: Polity Press in association with the Open University, 1992.

HOUNTOUNDJI, Paulin. Conhecimento de África, conhecimentos africanos: duas perspectivas sobre estudos africanos. In: SANTOS, B.; MENSESES, M. P. Epistemologias do sul, p. 119-132. Coimbra: Almedina, 2009.

\section{—. Endogenous knowledge: research trails. Dakar: Codesria, 1997.}

LANDER, Edgardo. Ciencias sociales: saberes coloniais y eurocéntricos. In: LANDER, E. La colonialidad del saber: eurocentrismo y ciências sociales. Perpectivas Latinoamericanas, p. 4-23. Buenos Aires: Clacso, 2000.

LATOUR, Bruno. Reassembling the social: an introduction to actor-network theory. Oxford: Oxford University Press, 2005.

LAW, John. After method: mess in social science research. New York: Routledge, 2004.

MAIA, Joao M. History of sociology and the quest for intellectual autonomy in the Global South: The cases of Alberto Guerreiro Ramos and Syed Hussein Alatas. Current Sociology, v. 62, n. 7, p. 1097-1115, 2014.

MAIA, J. M. E.; CARUSO, G. B. Uma trajetória intelectual periférica: Hussein Alatas e a sociologia autônoma. Perspectivas: Revista de Ciências Sociais (Online), v. 41, p. 53-77, 2012.

MAMA, Amina. Cuestionando la teoría: género, poder e identidad en el contexto africano. In: SUÁREZ NAVAZ, L.; HERNÁNDEZ CASTILLO, R. A. (Eds.). Descolonizando el feminismo: teorías y prácticas desde los márgenes, p. 223-244. Madrid: Editorial Cátedra, 2008.

MIGNOLO, Walter., The darker side of Western modernity: global futures, decolonial options (Latin America Otherwise). Duke: Duke University Press, 2011.

MOHANTY, Chandra. Under Western eyes: feminist scholarship and colonial discourses: In: MOHANTY, C.; RUSSO, A.; TORRES, L. (Eds.). Third world women and politics of feminism, p. 233-258. Bloomington: Indiana University Press, 1984.

NEVES, Fabricio. M.; COSTA LIMA, Jose .V. B. As mudanças climáticas e a transformação das agendas de pesquisa. Liinc em Revista, v. 8, p. 248-262, 2012. 
NYAMNJOH, Francys. Potted plants in greenhouses: a critical reflection on the resilience of colonial education in Africa. Journal of Asian and African Studies, v. 47, n.2, p. 129-154, 2012.

PATEL, Sujata. The ISA handbook of diverse sociological traditions. London, Sage, 2010.

QUIJANO, Anibal. Coloniality of power and eurocentrism in Latin America. International Sociology, v. 15, n. 2, p. 215-232, 2000.

ROSA, Marcelo C. Theories of the South: Limits and perspectives of an emergent movement in social sciences. Current Sociology, v. 62, n. 6, p. 851-867, 2014.

- Sociologies of the South and the actor-network theory: possible convergences for an ontoformative sociology. Paper, Presented at Anpocs Annual Meeting, 2013.

SANTOS, B.; MENESES, M. P. Epistemologias do sul. Coimbra: Almedina, 2009.

SCHMIDT, Volker H. Modernidade e diversidade: reflexões sobre a controvérsia entre teoria da modernização e a teoria das múltiplas modernidades. Sociedade e Estado, v. 26, n. 2, p. 155-183, 2011.

SMITH, Linda T. Decolonizing methodologies: research and indigenous people. London: Zed Books, 1999.

SPIVAK, Gayatri. Can the subaltern speak. In: NELSON, C.; GROSSBERG, L. (Orgs.). Marxism and interpretation of culture, p. 66-111. London, Macmillan, 1988.

SZTOMPKA, Piotr. Another sociological utopia. Contemporary Sociology, v. 40, n. 4, p. 388-397, 2011.

TAVOLARO, Sergio B. F. Existe uma modernidade brasileira? Reflexões em torno de um dilema sociológico brasileiro. Rev. bras. Ci. Soc., v. 20, n. 59, p. 5-22, 2005.

VERRAN, Hellen. Re-imagining land ownership in Australia. Post-Colonial Studies, v. 1, n. 2, p. 237-254, 1998.

WALSH, Catherine. Shifting the geopolitics of critical knowledge: decolonial thought and cultural studies "others" in the Andes. Cultural Studies, v. 21, n. 2-3, p. 224-239, 2007. 
